\title{
Educators' Explorations with Gender Performativities and Orientations: A Participatory Action Research Project in West Nile Sub-Region, Uganda
}

\author{
SHELLEY JONES \\ Royal Roads University
}

\begin{abstract}
This paper discusses findings from a feminist participatory action research study conducted in the West Nile region of Northern Uganda with a group of 35 educators who attended a one-week intensive professional development course focused on promoting gender equality in schools. Through a theoretical and methodological framework of multiliteracies and multimodality, gender constructs were "exposed" (Butler, 1988) and "disoriented" (Ahmed, 2006), opening new spaces for the promotion of gender equality, as well as pedagogical approaches to literacy that the participants could integrate into their own teaching practice to facilitate transformative learning in their own school contexts.
\end{abstract}

\section{Keywords}

gender and education; Uganda; professional development; multimodality; multiliteracies; performativity; gender orientation

\section{Introduction}

Sustainable Development Goal 5, Achieve gender equality and empower all women and girls, is testament to global recognition of the need to prioritize efforts that will challenge and change practices, behaviours, and structures (many long-held and culturally embedded) that have served to oppress and discriminate against girls and women. Education is understood as one of the (perhaps the) most powerful ways through which to promote and cultivate gender equality, and gender-focused initiatives are now pervasive in the education sectors of countries worldwide. In Uganda, gender-as a focus themehas been mainstreamed throughout national planning documents, such as Uganda Vision 2040 (Government of Uganda, 2007), and educational policies and documents such as the National Strategy for Girls' Education (NSGE) (Uganda Ministry of Education and Sports (MOES), 2013).

However, policies and documents in and of themselves do not disrupt normative gender(ed) structures and behaviours, or activate transformative social processes necessary to bring about gender equality. Disorienting gender within deeply patriarchal societies, such as Uganda, will entail no less than a radical deconstruction of the way things are and have been: gender equality can only truly be achieved if gender is exposed as a social construct that is "performed" (Butler, 1988) along "lines" (Ahmed, 2006) that have been forged and afforded particular forms of power (or oppression) and privilege (or subjugation) by history and culture and that can be "disorientated" in order to be reorientated (Ahmed, 2006). Educators in such contexts, as frontline proponents of gender equality, have a dauntingly complex task. They must themselves begin to understand orientations of gender before they can effectively work towards challenging the inequalities associated with those orientations. And because their own identities have been shaped by 
sociocultural and historical constructs around gender, educators require opportunities that will enable them to conscientize (Freire, 1970) their own gendered identities by "expos[ing] the reifications that tacitly serve as substantial gender cores or identities" (Butler, 1988, p. $530)$.

This feminist participatory action research study, conducted with educators in the West Nile sub-region of rural Uganda during a one-week professional development course (held in October 2014) concerned with the topic of gender-responsiveness in the school environment, sought to open up a new space for understandings of gender through multimodal literacies that "disoriented" the normative approaches (e.g., formal, powerdifferentiated discussion forums) to discourse engagement. During this course, the participants engaged in multimodal activities - writing, drawing, drama, and discussionsthrough which they explored and reflected upon the depth, breadth, and nature of gender inequalities that existed not only in schools, but in society at large. This paper will focus on the participants' experiences of performing and disorienting gender and insights gained into gender constructs that perpetuate gender inequality.

\section{Structure of the Paper}

In the following sections I describe the Ugandan context within which this study took place, and the theoretical perspectives of performativity (Butler, 1986), orientation (Ahmed, 2006), and a multiliteracies (New London Group, 1996) and multimodal understanding of text and literacy pedagogy. I then discuss the reasons for choosing a multimodal methodology that emphasized embodiment to explore constructions and assumptions around gender and the ways in which these negatively impact girls' educational experiences and opportunities.

In discussing findings from the research, I explore the ways in which the participants understood concepts of gender, gender equality and gender inequality, as well as the ways in which gender constructs orientate the participants themselves during these discussions. Their embodiment of the gender orientations and behaviours under consideration offered opportunities for innovative approaches to pedagogical practices that challenged the dominant, normative practices. Opportunities for embodiment of unfamiliar orientations through drama facilitated the creation of multimodal 'text' that sedimentized new learning and experiences through praxis (Rowsell \& Pahl, 2007). I conclude with some observations and recommendations about the enormous potential for embodiment as a means by which text can be created, read, and used for transformative learning.

\section{Background}

\section{Research summary}

Gender inequalities exist in countries and cultures throughout the world, but they differ in manifestation in accordance with the context. In Uganda, diverse and wideranging gender discrimination is acknowledged as being enormously detrimental to girls' educational and life opportunities, and thus over the past two decades the promotion of girls' education and gender equality has received a great deal of attention at the policy level, as well as through various national and international initiatives.

At a national level, Uganda has made significant gains in girls' access to and enrolment in education, having achieved near to full gender parity at both the primary and secondary school levels (Kwesiga, 2003; Uganda Ministry of Education and Sports, 
(MOES), 2013; UNESCO, 2017) ${ }^{1}$. Nevertheless, gender inequality remains highly problematic in Uganda (Blackden, 2004; Bantebya, Muhanguzi, \& Watson, 2014; Uganda MoGLSD, 2007; Uganda MOES, 2015; UNDP, 2015), and there are marked regional and socioeconomic disparities (Lawson, 2003; Ugandan Bureau of Statistics (UBOS), 2017). The West Nile sub-region of Uganda has the highest gender gap in enrolment in the country, with only six girls in school for every ten boys (Uganda BOS, 2015). Reasons contributing to girls' lack of attendance in the West Nile sub-region, and common throughout Uganda, include: the need to assume an unfair burden of domestic duties (MOES, 2015; Jones, 2008, 2011; Stoebenau et al., 2015); costs related to schooling, such as uniforms and school supplies (Jones, 2008, 2011; Stoebenau et al., 2015); distance to school and associated risks (e.g., sexual assault, harassment) (Geiger, 2002; Jones, 2008, 2011; Uganda MOES, 2015); and boys' education prioritized over girls' within families (Jones, 2008, 2011; Stoebenau et al., 2015), as well as girls' own perceptions of their abilities (Stoebenau et al., 2015).

Systemic gender discrimination that limits girls' educational opportunities is openly acknowledged:

The school system remains a dominant source of gender bias and stereotyping. Education processes are instilled with persistent and inbuilt gender differences. Females and males are subjected to deferential socialization in classrooms and are rewarded for different things. Girls tend to be directed at learning and reinforcing femininity thereby learning to be submissive and passive instead of being independent and thoughtful. As a result the schools are largely unable to provide a gender responsive environment for effective teaching and learning to take place. (Uganda MOES, 2015, p. 16)

Didactic pedagogical approaches that center around closed questions, memorization, exam-based teaching, and obedience in the classroom have a particularly negative impact on girls who are expected to be "submissive" and defer to males (Kakuru, 2006; Mirembe and Davies, 2001; Mlama, P. et al., 2005). Teachers' attitudes that girls are not as intelligent or capable as boys are not uncommon (Geiger, 2002; Jones, 2008; Mirembe and Davies, 2001). And, books and other learning materials often reinforce gender stereotypes (Mlama et al., 2005; Jones, 2015). In addition, girls are also often expected to take on extra duties at school (e.g., serving tea to the teachers, washing dishes, cleaning the compound), which are not expected of boys, reinforcing girls' sense of servitude (Jones, 2008). Furthermore, sexual harassment, assault, and exploitation in the school context by male students and male teachers, and during the commute to school by boys and men in the surrounding areas, are common (Mirembe and Davies, 2001; Mlama et al., 2005; UgandaMOES, 2015; Jones, 2008, 2011). In the West Nile region of Uganda, girls' attendance and retention in school are particularly problematic (Faughnan, 2016; UBOS, 2012; Stoebenau et al., 2015).

Increasingly, it is becoming understood that gender equality in education must

\footnotetext{
${ }^{1}$ It must be noted, however, that although net and gross enrolment rates for both females and males is relatively high at the primary school level, primary completion rates for females are low, as is secondary school attendance.
} 
ensure that girls can claim and exercise their rights to freedoms, opportunities, power, aspirations, and control over their own bodies and lives. The goal of the NSGE and other related policies and initiatives is to create gender-responsive schools and learning environments that liberate children from gender-related oppression and limitations. But, in order to be prepared to create authentic learning spaces of gender equality and empowerment, educators themselves need to engage with lived experiences of gender equality/inequality as embodied knowledge and sensation at deeply personal levels to reflect upon and deconstruct their own normative gender assumptions. They must be supported in a journey that may facilitate a renewed, even transformative, understanding of their own gendered identities.

\section{Theoretical Perspectives}

The theoretical perspectives I draw upon to understand the complexities and possibilities of gender constructs include Judith Butler's (1988) theory of gender performativity, "disorientation" within Sara Ahmed's (2006) theory of "queer orientation," and Rowsell \& Pahl's (2007) conception of understanding of text as "sedimentized," multimodal expressions of embodied knowledge, and a multiliteracies conceptualization of literacy as meaningful engagement with text (New London Group, 1996).

\section{Gender Performativity}

Gender is a social construct that is at the same time both deeply personal and highly public. Gender(ed) constructs frame the very ways in which we know ourselves and the world, as well as the way in which the world knows and interacts with us. Everyday behaviours (such as gestures, speech, and conduct), as well as pervasive roles and responsibilities (such as domestic duties and financial control), are gendered: "Gender is what is put on, invariably, under constraint, daily and incessantly" (Butler, 1988, p. 531). These continuously repeated performative acts of gender create patterns and narratives that shape understandings and self-concepts that essentialize what it means to be female or male so that gendered behaviours and dispositions appear to reflect a substantive and inherent aspect of the individual. Butler (1988), however, argues that "stylized repetition of acts" (p. 519) are not signifiers of "stable identities," but rather represent "a constructed identity, a performative accomplishment which the mundane social audience, including the actors themselves, come to believe and come to perform in the mode of belief" (Butler, 1988, p. 520; emphasis added).

\section{Gender Orientations}

Ahmed (2006) argues that understanding gender constructs and the ways in which they shape our lives is determined by the way in which we are "oriented" in space and to objects. The spaces we inhabit in our daily lives - our homes, our places of work, and our communities - are familiar and predictable to us. These familiar spaces become the background upon which our bodies and the objects with which they interact are foregrounded. The ways in which our bodies are able/unable to occupy space, and the objects (material as well as immaterial) with which we interact and towards which we are oriented to/around/away from, as well as the distal relations between our bodies and those objects, serve to facilitate or constrain our freedoms and opportunities. 
Objects are what we "do things with" and what allow us to do things; they can be material or immaterial (e.g., personal goals, hopes, opportunities). They are located (or placed) upon/within the background in ways that have particular orientations (time, distance, angles) to us. Objects that are nearest to us are given our greatest attention to, and often what is nearest to us has been placed there. What is placed near to children is what society intends them to reach towards, to follow the hereditary "straight" line which reproduces normative societal structures:

we...inherit the proximity of certain objects, as that which is available to us, as given within the family home. These objects are not only material: they may be values, capital, aspirations, projects, and styles. Insofar as we inherit that which is near enough to be available at home, we also inherit orientations, that is, we inherit the nearness of certain objects more than others, which means we inherit ways of inhabiting and extending into space. (Ahmed, 2006, p. 557)

In the context of a girl's experience, objects that are placed in close proximity to her will influence the nature of, and frequency of her interactions with it, and she will extend herself in space towards what those objects represent. The placement of an object leads the body towards it in a particular line. For girls in the rural Ugandan context, for example, brooms, washing basins, and cooking pots are frequently at hand, and girls learn to orientate themselves towards cleaning and cooking, caring for others, and focusing their attention on the home, in accordance with the normative and hereditary gender line of society.

Individuals also orientate themselves toward or around immaterial objects such as beliefs, self-confidence, values, and personal goals depending on the proximity, accessibility, and availability of those objects to the individual. In rural Uganda it is often, perhaps generally, expected that girls are meant to prioritize becoming wives and mothers over education - at the post-secondary, secondary, or even primary level. Such strong, prevalent cultural expectations (immaterial objects) work together with material objects (such as brooms, basins, cooking pots) to orientate girls towards marriage, motherhood, and domestic duties. This strong orientation towards domestic responsibilities serves to orientate girls away from other immaterial objects such as personal goals, aspirations, and careers) because the lack of orientation has prevented critical connection and familiarity with these objects. Thus, girls begin to understand what is within reach for them through these orientations: "The normative can be considered an effect of repeating bodily actions over time, which produces what I have called the bodily horizon, a space for action, which puts some objects and not others in reach" (Ahmed, 2006, pp. 561-2).

The ease with which a body can move through space determines what is within reach of/for that body. Ease and normativity converge in alignment where the straight or normative body aligns with vertical line and conforms to the normative space. Children's bodies and attention are directed towards particular "lines," or lineages, or life paths that have histories and are etched-often deeply_-within within the social architecture to promote the continuation of the line. The lines have been created, or have evolved to frame and hold society together with a particular orientation of what is normative/straight. Objects that have relational significance to particular orientations are also integrated into those lines that with history seem not to have been created, but to have always existed. 
Thus, the lines come to represent an orientation of normativity where relationships between bodies and between bodies and objects appear stable, aligned, and balanced. As such, these lines offer both an illusion of inevitability (that one inherits certain lines to follow), and of choice (that there is a range of lines to choose from), and yet these lines are not hereditary nor are they easily resisted. These lines offer certain benefits that can only be enjoyed if the line is followed; and, there is pressure to conform to these lines to ensure that the hereditary societal structures are perpetuated. However, horizons are constructed, over time, to establish normative orientations. The horizontal axis is what determines the orientation of the vertical (body) within space.

Unsurprisingly, the spaces, objects, orientations, performativities, and lines that intersect, viewed from a normative, paradigmatic perspective that has a vested interest in aligning individuals to prescriptive social norms (e.g., to perpetuate patriarchal power and privilege), resist disorientation (e.g., erode patriarchal power and privilege and support women's empowerment) to maintain and enhance the status quo. Thus, individuals/bodies that deviate from or challenge the normative alignment of the horizontal and vertical will encounter difficulty extending into space and will find many objects out of reach.

Ahmed (2006) posits that it is necessary to intentionally disorientate the familiar in order to expose the coherence and calcification of normativity as a constructed state that has been reified through performativity, lines, and objects, and not an originary state. Exposing and disavowing gender-normative beliefs (for self and others) and associated practices/performances can be radically disorientating. In contexts such as rural Northwest Uganda, where girls and women's orientations and alignments are very much constrained by patriarchal norms that subjugate women to subservient positionalities where personal dreams and freedoms are deemed out of reach (by themselves as well as others), there is little scope for a young girl to challenge these entrenched societal orientations without repercussions or even grave risk, if there is no support for her to do so.

Thus, it is incumbent upon adults, especially teachers who represent learning, knowledge, and possibilities, to support children in questioning normative values, beliefs, behaviours, and structures. Only through disorientation does one become aware of one's orientation (Ahmed, 2006). It is necessary to expose the normative orientations that have created, perpetuated, and entrenched gender inequalities in order to begin to figure out a way to actually bring about gender equality. Gendered identities can be de/re-constructed by creating new lines that do not follow, or reproduce, existing lines or paths. In order to grapple with orientations, however, we need to begin to with ourselves, "the here of the body and the where of its dwelling" (Ahmed, 2006, p. 545).

\section{Text and Literacy as Embodied Social Practice}

Understandings of literacy have expanded over recent decades with the acknowledgement that meaning is communicated through a wide range of literacies, or multiliteracies associated with a "plurality of texts" (New London Group, 1996, p. 61), which are representative of diverse cultures and contexts:

Apedagogy of multiliteracies ... focuses on modes of representation much broader than language alone. These differ according to culture and context, and have specific cognitive, cultural, and social effects . . Multiliteracies also creates a different kind of pedagogy, one in which language and other modes of meaning are 
dynamic representational resources, constantly being remade by their users as they work to achieve their various cultural purposes. (New London Group, 1996, p. 64)

With this expanded understanding of semiotic representation comes an expanded notion of "text."

As multiliteracies acknowledges the various forms and engagement with literacy, multimodality (Kress \& van Leeuwen, 2001; Kress \& Jewitt, 2003) is a framework that acknowledges the importance of the elements involved in creating meaning (or "text") within these different kinds of literacies. Multimodality assumes as a fundamental tenet that literacy is not limited to meaning conveyed through prescribed forms of written or spoken language, but through a wide range of semiotic representations that are produced by the meaning-maker through their choice and combination of semiotic modes, such as drama, drawing, dance, photography, and music (Kress \& Jewitt, 2003; Kendrick, Jones, Mutonyi \& Norton, 2006).

Kress \& van Leuwen (2001) state, "the semiotic instances, or texts, in which we are interested include the everyday practices of "ordinary" humans as much as the articulations of discourses in more conventionally text-like objects" (p. 24). Rowsell \& Pahl (2007) posit that these texts are representations of the meaning-maker's habitus (Bordieu, 1977, 1970), or, "ways of being, doing, and acting in the world across generations, time, and space" (Rowsell \& Pahl, 2007, p. 391). As such, the texts become material "sedimentation" (Rowsell \& Pahl, 2007) of identity, and insightful commentaries on the Discourse(s) (Gee, 1996, 1999) with which she is engaged.

The semiotic act of producing and interpreting a sign involves an interweaving of diverse modes (e.g., sound, movement) that are embedded within a context (e.g., a classroom) that create an embodied experience for both the sign-makers and the signinterpreters, and create communicative forms in ways unique to the sign-maker. The textmaking process involves the active integration of these components through "praxis" (Rowsell \& Pahl, 2007), which offers opportunities for deep learning and "the expansion of identities ... [that can] be accompanied by a transformation in the identities of the text maker"(Kress, as cited in Rowsell \& Pahl, 2007, p. 393).

Alternative modalities of expression disrupt normative power structures that are founded upon, bounded, permeated, and perpetuated by formal and exclusionary literacy practices that prevent those not versed in those practices from having a voice. A multimodal and multiliteracies approach to literacy pedagogy opens possibilities for meaning-making and contributions to Discourse from those often excluded from discussions and decisions that impact their lives and their communities. In this study, participants drew upon their habitus, identities, and the gender discourse under consideration, and used a range of modes to sedimentize experiences, observations, and ideas into signs that were shared with and interpreted by others within the embodied context of the course. Importantly, the act of creating and interpreting meaning in a multiliteracies/multimodality approach to literacy also introduced new pedagogical approaches to literacy for the participants that they could incorporate into their own teaching. 


\section{Participants and Location}

\section{Research Design and Methodology}

This research project involved 30 pre-primary and primary school educators in the West Nile sub-region of Northern Uganda. These educators were interested in promoting gender equality in their schools and voluntarily attended a one-week professional development course (October 2014) on the topic of gender-responsive pedagogy, that I designed and facilitated. The course was offered as part of an East African educational initiative funded by the Canadian government's Department for Foreign Affairs, Trade and Development (DFATD) and operationalized by the Aga Khan Development Network. This program focused on areas in East Africa where education was particularly problematic in terms of attendance, retention, performance, and gender inequalities.

The participants in this course included male and female teachers and head teachers, as per the table below.

Table 1

Feminist, Participatory Action Research Framework.

\begin{tabular}{|l|l|l|l|}
\hline Designation & Female & Male & Total \\
\hline Head teachers & 1 & 4 & 5 \\
\hline Pre-primary teachers & 9 & 6 & 15 \\
\hline Primary Teachers & 10 & 5 & 15 \\
\hline
\end{tabular}

A feminist, participatory action research (FPAR) multimodal methodology was used in order to engage participants in the investigation of gender issues they had both witnessed and experienced themselves. The FPAR approach is a "[d]ecolonising research [process that] ... helps envision other ways of theorizing the complexity of gender and educational experiences" (Chilisa and Ntseane, 2010, p. 630). As a white, female, Canadian course facilitator and researcher, I fully and openly acknowledged and inhabited my etic positionality as well as my cultural and personal lens and biases. I discussed gender inequality as a global phenomenon in order to position Uganda within the larger context of the world. As one participant remarked in their reflective summary of the course, "There was good comparisons between issues within Uganda and issues which were outside Uganda which widen the scope of understanding of the participants".

I established my role as that of a facilitator, and made clear my intention for the participants and me to work together equally as investigators of gender-related issues. In alignment with fundamental tenets of participatory research., I also acknowledged that the participants were the experts with respect to the local contexts in which they lived and worked and so my role was primarily to listen and work with them to address the issues of gender inequality that they identified: 
The researcher's role as a privileged possessor of expert knowledge must be reconceptualized as that of a catalyst who works with local participants to understand and solve local problems. The researched become as important as the researcher in formulating the problem, discussing solutions, and interpreting findings." (Hall, 1975, as cited in Lather, 2004, p. 200)

A Ugandan educator who had completed her Masters of Arts degree in Education at the Aga Khan Institute for Educational Development-East Africa co-facilitated the course with me in her role of Professional Development Tutor. Her familiarity with diverse education contexts as well as gender-based constructs in Uganda helped me to gain deeper insight into some of the issues raised by the participants.

The FPAR approach also examines a question or problem-in this case gender inequalities - from a vantage point that seeks to uncover the various intersections of, for example, cultural practices, resources, policies, and institutions, in order to bring about change. FPAR often involves, as was the case in this project, "organizational building" (Maguire, 1996), where solidarity amongst the community needed to be cultivated in order to open up the research topic. During the week-long professional development course which is the focus of this study, a mixed-methods, multimodal approach was used for data collection. The participants completed pre- and post-course questionnaires, a reflective summary on the week's activities, and they engaged in a number of multimodal activities during the course, in which they contemplated their own embodiment of gender-based experiences and assumptions.

\section{Multimodality as Methodology.}

In this study I draw upon multimodality as a methodological framework. Multimodality, or, meaning-making through different modes (e.g., images, writing, and speech) and media (video, drawings, drama), offers a creative, investigative, contextresponsive approach to explore the complexities of gender. Multimodal activities provide opportunities for expression and reflection that extend far beyond the traditional, hegemonic and often patriarchal discourses which are typically mediated by language (spoken and/or written), particular kinds of language (e.g., an official language that denotes an educated individual, or a dialect that is considered of higher value than other dialects), and language acts (such as public debate or official pronouncements).

Multimodality actively seeks to engage individuals in self-expression that intentionally subverts predictable and limiting structures of language and its modes of representation (writing and speech) to a diverse range of semiotic (meaning-making) modes (Kress \& Jewitt, 2003). Modes are gestures, images, sounds and other such material representations that constitute "organized sets of semiotic resources for meaning-making" (Jewitt, 2008, p. 246) and thus a form of text, whose meaning can be read, or co-created, by its audience. The texts, or artifacts, become semiotic points of engagement that stimulate perceptions and sensations in others (Pink, 2011; Roswell \& Pahl, 2007).

Data collection included: pictures created by participants; video recordings of dramas; stories written by participants; observations of activities recorded by written notes taken by me; chart paper used to record ideas and main points of discussion; notes take by me during discussions; participants' reflective writing on the week's activities; and a 
course evaluation completed by participants.

\section{Analysis}

There were three levels of data analysis, all of which used a triangulation design analysis approach (Cresswell, 2008). One level of analysis focused on data pertaining to gender issues in local educational contexts as identified by the participants. As data were produced, participants and I together reflected upon emergent themes, which I recorded and coded into categories relating to gender discrimination in the educational context (such as inferior status/home, inferior status/school, and inferior status/community). This analysis process was iterative (Grbich, 2013) and collaborative.

A second level of analysis focused on my interpretations of the engagement and experiences of the participants themselves as they immersed themselves in the production and interpretation of multimodal texts that disoriented normative gender constructs. After various sessions in the course, I would reflect upon my observations of various "texts" (semiotic representations ranging from behaviours, to artifacts, to spoken words) that had been produced and then present my thoughts and questions around these texts to the participants for their consideration. The analysis here-although initially conducted by me-was ultimately collaborative.

A third level of analysis included grouping quantitative findings from the pre- and post-course questionnaires according to predetermined codes based on close-ended questions, as well as sorting and coding emergent data from open-ended questions on these questionnaires, my observation notes, and the reflective writing pieces the participants composed at the conclusion of the course. This was also the stage of meta-analysis, involving extensive triangulation, as I worked with the various data sets to confirm assertions, expose any contradictions, and formulate new questions.

\section{Findings and Discussion}

Findings from this study revealed that all the participants were well aware of the wide-ranging forms of gender injustices (physical, emotional, mental) suffered by girls (and by some of the participants themselves) in their schools and communities. The participants could identify material "objects" (e.g., learning and financial resources, household items) as well as immaterial "objects" (e.g., practices, behaviours, attitudes, opportunities) that were orientated towards/against girls in ways, as well as performances of gender that excluded, marginalized, oppressed, or even violated them. However, the participants did not identify the underlying gender constructs that framed the space of these orientations and performances. Thus, the multimodal activities described below discuss how the participants began to engage with gender constructs and gain deeper understanding of gender-related issues in their own lives as well as in their educational contexts.

\section{Performativities and Orientations of Space and Voice}

The first day of the course involved reviewing understandings of gender and consideration of what gender-responsive schools might look like. Overwhelmingly, the male participants dominated the discussions and responses to the questions, often overriding the female participants' attempts to make contributions. This had quickly become a space into which men extended themselves and exercised the gendered power that it afforded them. The men's bodies were vertically aligned with the horizon (the space 
of public discourse), but the women's bodies were not. This was a useful place to begin the course as the performativities and orientations related to gender had naturally unfolded: "The starting point for orientation is the point from which the world unfolds: the here of the body and the where of its dwelling" (Ahmed, 2006, p. 545).

The following day I requested that all participants reflect upon why women were less likely to respond and voice their opinions than men in this kind of context. Each participant wrote an anonymous response and taped it on the wall. This was followed by a gallery walk where the responses were read. A number of responses asserted that women did not have the confidence to contribute their ideas in public and/or formal contexts: "Women are shy; women are fearful"; "women tends to be shy among men"; "The women are generally fearful. They think men can present better than them"; "Women still feel inferior in the presence of men so therefore fearing to take responsibility; low self-esteem in women to talk out what they think; awareness about gender equality missing among the women; fear of being just a woman among men." Some responses attributed to men greater ability and/or intelligence than women: "men are quick in decision taking"; "Women feel men can do better than them"; "[Women] believe that men are the leaders; Others think that men's are more intelligent than them"; "Women takes a lot of time while explaining"; "Men feel that sometimes what women does can not be understood." Others claimed that cultural norms positions men in a place of power over women, where women feel they must "respect" (often a euphemism for "obey") men and assume a deferential and subordinate role: "African culture of paying respect to men"; "The women generally give respect to men by allowing them to lecture"; "the women have respect for the men to make men stand and represent them"; "Others [women] feel ashamed to stand in front of men; the cultural belief that men are ahead of women . . . the cultural belief that men are over all of everything"; "The African tradition discourages women's voice"; and, some stated simply that women are not given opportunity" and that the men did not give them chance to present."

These honest, anonymous, acknowledgements of feelings and, reasons/excuses for the oppression of women's voices opened up the opportunity to explore the constructs underlying these performativities, objects, and orientations. Gendered orientations and performativities related to voice/voicelessness in public space had been exposed. Women's orientation towards/within the space were characterized by fear, shyness, deference to men, shame, and inadequacy, and these orientations were performed by "allowing [men] to represent them," and "tak[ing] a lot of time" to express their ideas. For the men, on the other hand, their orientation toward/within the space enabled them to "lecture" and assume leadership roles. This was performed by being "quick in decision taking," and "not giv[ing] [women a] chance to present." In the ensuing discussion, some of the women ventured to express their frustrations with men talking over them, cutting them off when they were speaking, or dominating discussions. Several of the men objected to these claims, but because the intersectionality of gender, voice, and power was now under consideration, the associated gender constructs that provided men with dominant positionality and greater power had become conscientized and acknowledged as a representation of gender inequality.

The participants acknowledged that these gendered performances and orientations were also existent in the school context, where the horizon aligned with male students (in terms of, for example, offering ideas, responding to questions, receiving support and 
encouragement from teachers) and male teachers and administrators (who were given greater respect and whose ideas were received with more serious consideration). Girls, on the other hand, were often overlooked or not encouraged to contribute to class discussions/questions, expected to be submissive, and defer to boys and men, and not given equal respect as boys. Female teachers as well were expected to be subordinate to male teachers and administrators as per cultural expectations.

In order to redress this imbalance - both in this professional development situation and in the school context - the participants proposed various responses and approaches that could be taken to promote a supportive and inclusive environment to overcome feelings of intimidation and vulnerability. Participants' suggestions included: providing more time for girls/women to speak; awareness of the ratio of responses between girls/women and boys/men and making efforts to ensure these were equal and proportionate; drawing awareness and not tolerating boys/men interrupting, talking over girls/women. (Of course, these same approaches could be applied to girls/women who might dominate boys/men.) Such deliberate efforts to open up space and time for girls' and women's voices to be heard would serve to disorientate the normative educational context.

\section{Disorienting the Performativity of Space and Voice}

Although the women's voices had been "heard," the challenge of ensuring that their voices continued to be heard and extended in the shared space remained. The horizon of the space that had been established - that of public discourse - had the male body, but not the female, aligned at its vertical intersection. So, with the intention of unsettling the gendered power dimensions that had surfaced, I attempted to re-orientate the parameters and constitutional elements of that space, by shifting the familiar axes sufficiently so that gender performativities as enacted by the participants might be exposed.

In order to facilitate more equitable participation in the classroom setting, I initiated a two women per one man ratio (a ratio reflective of the gender female/male numbers in the group) of contributions to discussions and responses to questions. This was very challenging to implement at the beginning: many of the men were demonstrably annoyed with this approach, and became agitated and impatient when they were forced to wait to for women to make their contributions before they could respond. And, many of the women were initially timid and/or reticent to express their thoughts and offered responses in very quiet voices or whispers, kept their heads low, or asked a female peer to answer on their behalf. However, over the course of the week, the contributions of women who were initially reluctant to put forward their views increased significantly. In addition, the men, especially the headteachers, who were typically accustomed to assuming roles of leadership, authority, and representation of others, became more patient and supportive of their female colleagues. The body language also shifted: the men were more relaxed when waiting for women to respond, and the women began to respond in louder, more confident voices, making more eye contact with other participants - including the men - in the room.

The majority of the participants expressed appreciation for this intentional strategy for including all voices in discussions and activities. In his reflective summary, one man commented that one of the highlights of the course was, "Woman/woman/man answering questions planted some confidence, morale in the women to talk. It was interesting and encouraging." A woman similarly commented that one of the enjoyable things about the course was, "Answering questions and contributions woman/woman/man."Another 
woman observed that "Woman/woman/man answering questions/contributions gives chance for women to know that they can also think like men; made women to feel that they are also powerful and good decision makers; made women to feel that they are equal to men". These comments reveal that although the normative orientation remained masculinist — in that power, ability, and opportunity was framed around men — women had an opportunity to experience male orientation in this context and thus trouble the assumptions that aligned men (and not women) to its horizon. Many participants said that, when they returned to their classrooms they would "Giv[e] equal opportunity for girls and boys in discussing questions in class," indicating their willingness to begin to disrupt gender orientations in their classrooms.

However, there are limitations to structural strategies and processes that are implemented in attempts to manage and distribute power and opportunities in a controlled environment, as they do not subvert the foundational social architecture of gender and associated power imbalances. In order to "expose the reifications that tacitly serve as substantial gender cores or identities" and disorient the normative, it is necessary "to elucidate both the act and strategy of disavowal which at once constitute and conceal gender as we live it" (Butler, 1988, p. 530). The written statement made by one participant- "The African tradition discourages women's voice"-with respect to women's reluctance to participate in discussions revealed an underlying driver of gender orientation which we explored as a group. We considered historical, cultural expectations of girls and women (the hereditary lines of gender) and how girls and women perform these expectations, how they position themselves within their society and relationships (how they orientate their bodies towards objects and how their bodies are orientated in relation to the horizon of normativity), and how these expectations, positionalities, and orientations impact the life paths, experiences, and opportunities of girls.

\section{Drawing as a Semiotic Mode to Identify Gender Inequalities}

To explore experiences of gender discrimination and stereotyping, the participants represented scenes where they had witnessed or experienced gender discrimination, particularly connected to educational environments and/or opportunities through drawings. They then taped their drawings to the wall and took time to view each of the images through a gallery walk. The images were raw and powerful, representing a range of gender-based abuses endured by girls within school and community contexts.

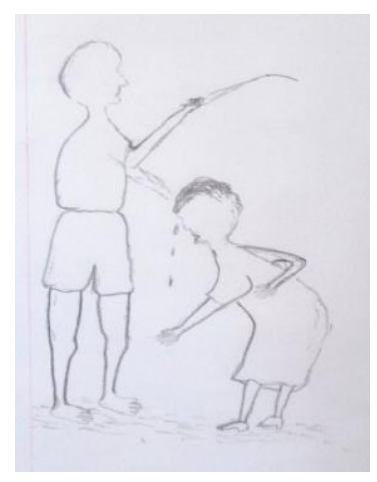

Figure 1. Male teacher beating female student 
Figure 1 represents physical abuse that girls are commonly subjected to by male teachers. In this drawing the male teacher is oriented towards and embodies power (dominant gender) and authority (teacher). The stick is a material object of orientation with which he performs power and authority by beating the girl. The girl, on the other hand, performs powerlessness (dominated gender), and she is (as are her tears) oriented towards the ground as she is beaten.

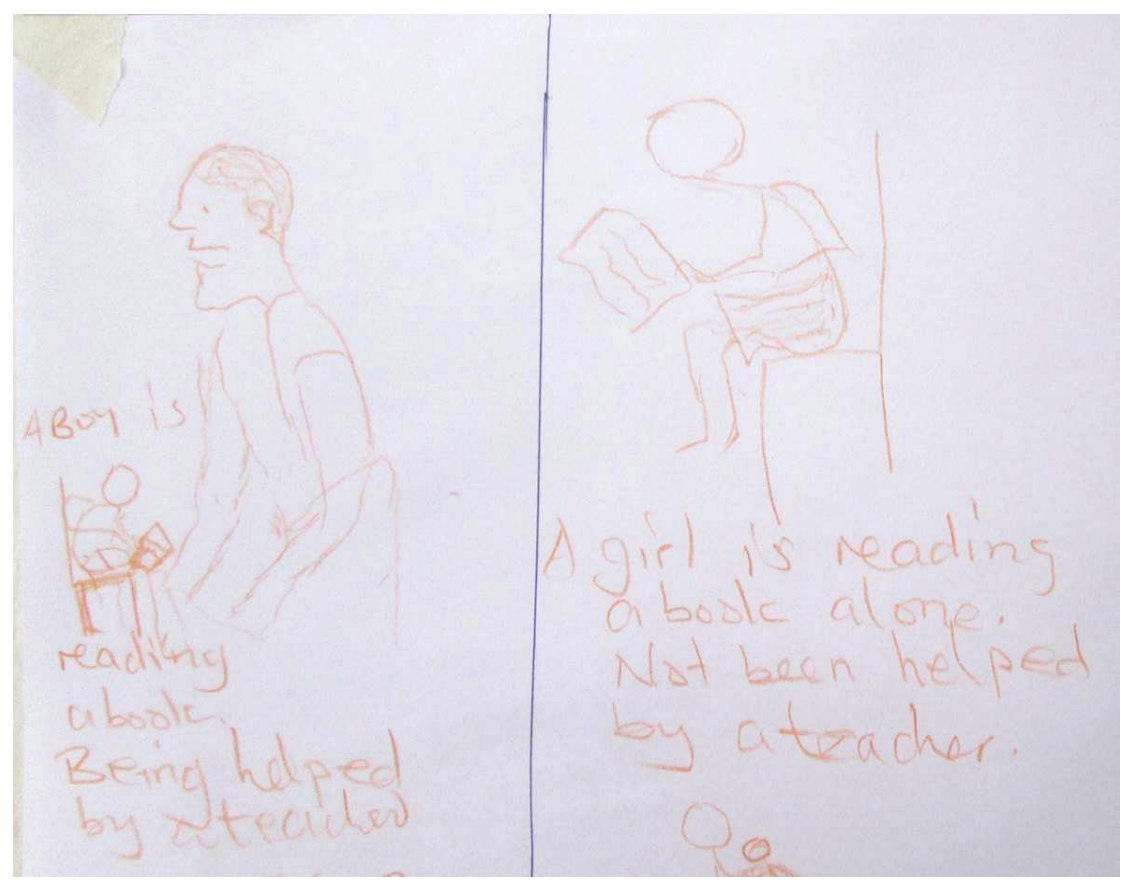

Figure 2. Contrast of attention given by teacher to boy and girl in classroom

Figure 2 contrasts the learning experiences of a boy and a girl in a classroom. On the left, the boy is receiving support and guidance from a teacher. The teacher is oriented towards the boy, who is, in turn, oriented towards the teacher who is nearby, in reach, of the boy. The boy performs the role of a student deserving of help, and the teacher performs the role of the one who is meant to provide help to deserving students. The right side of the drawing depicts a girl who receives no help or attention from the teacher. The girl is isolated, and the teacher is not within reach. The girl performs the role of someone who is not perceived as a student, but someone excluded, forgotten, and ignored. 


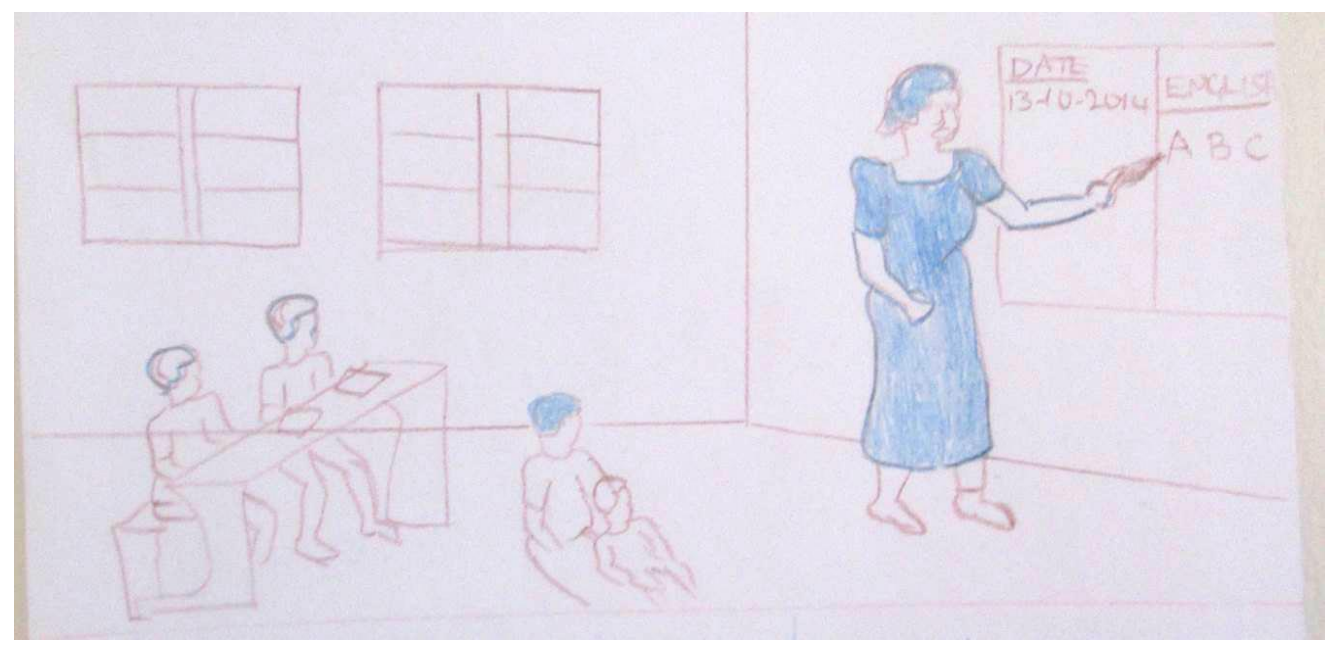

Figure 3. Girl and boys seated in classroom

Figure 3 depicts a classroom context in which the boys are seated on benches at desks, while the girl must sit on the floor. In addition, the girl is caring for a young child, possibly the child of the teacher, as this is not an unusual practice. In this drawing, the material objects of orientation are powerfully present. The boys are afforded higher status in the classroom by being provided with benches to sit on, and a desk upon which they can do their work. The benches afford the boys literal height over the girl, who is orientated towards the ground, upon which she sits. The girl is also orientated towards the child, whom is prioritized over the girl's educational opportunity. The teacher is oriented towards the boys, but not the girl.

Figure 4 (below) shows a boy lifting the skirt of a girl, representing girls' sexual vulnerability, and the sexual harassment and abuse they suffer from boys as well as men in the community (including teachers). The boy's performance of violating a girl's body is demonstrative of his orientation towards power over others' bodies. The girl's experience of having her body violated reflects her orientation away from power, or her orientation towards powerlessness and subservience. Even the object of the skirt itself - that girls must wear, both as part of the uniform as well as for everyday attire (even working in the fields) - as something that can be "lifted" in order to expose the body, represents the vulnerability and potential for sexual abuse that girls and women face. 


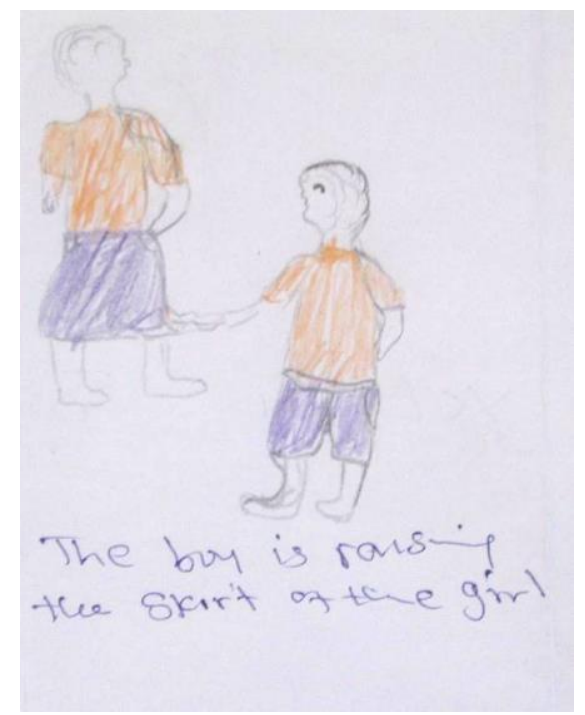

Figure 4. Boy sexually harassing girl

Following the gallery walk, discussion of the drawings revealed that all of the participants were familiar with each of the themes, and acknowledged that they were not uncommon in the school environment. In addition, many of the women alluded to their own personal experiences with the abuses depicted in the drawings. ${ }^{2}$ The discussion these drawings triggered was profound, and the unequivocally gendered nature of the injustices depicted was acknowledged by every participant.

\section{Disorienting Gender Through Drama}

Building upon themes that had been raised through the various activities, the participants explored and embodied gender(ed) experiences through drama. The participants worked in groups of five, and created short pieces that centered around one of the themes that had been presented through the drawings and/or discussed in the course: a talented female student was not given time at home to do homework; a male teacher sexually abused a female student; a girl became pregnant and was forced to leave school, but wanted to return to school; a girl who had missed many days of school due to menstruation and tried to attend school during her menstrual cycle, but her uniform became stained by menstrual blood and she was humiliated by the boys and then ordered to leave school by her teacher; and, the drama upon which I have chosen as a focus for analysisa girl had been denied a chance to begin school at the appropriate age, but when her mother finally convinced her father to allow the girl to attend school, she is "big" and is ridiculed by both the children in the class as well as the teacher.

Interestingly, in each skit, some participants chose to assume different genderroles for themselves. There was much laughter and teasing in the preparatory/rehearsal stages where women and men exchanged garments and created props to assume gender roles and disrupt their own gendered identities. This process led to some interesting insights into the ways in which they intuitively understood the performativities and orientations towards

\footnotetext{
${ }^{2}$ It would be helpful to further explore female teachers' own experiences of gender discrimination, but there was not sufficient time, nor appropriate conditions, in this study.
} 
objects associated with gender constructs. The dramas themselves explored some dark aspects of gender discrimination and revealed some disturbing realities.

The drama I will consider for analysis focused on a girl (played by a man) whose father (played by a woman) had not permitted her to begin school. The mother and daughter begged the father to allow the girl to attend school, but his response was to beat his daughter and force her to perform onerous domestic labour. In this drama, the material objects of orientation for the father were the suit jacket and trousers (which had been borrowed from a male participant), the chair upon which he sat, the food he ate, the copious amounts of alcohol he consumed, and the money he kept to himself and then dispensed to the girl only so that she could purchase more alcohol for him. With these objects, and the opportunity to occupy space as a man, the woman who played the father vertically aligned her (the man's) body easily to the horizon of scenario. She/he sprawled over the chair in a posture of entitled belligerence, and regularly extended a foot or a hand to kick or hit the girl, and demonstrated contempt and utter lack of compassion and respect for his wife and daughter.

The father/husband extended his power and dominance into the space of the home, where there was little, if any, space for the women to claim power. The wife and daughter were orientated around/toward the ground: they sat at the man's feet and pleaded with him, or scurried away from the place of power (the chair, the home) in order to do his bidding (e.g., buying more alcohol). The man who played the daughter embodied the performativity of gender associated with being a girl. Material objects of orientation included a skirt, a cooking pot, and a broom. With seeming ease, the man inhabited the vertical line against the horizon of the familiar space that girls inhabit. His/her movements were cowering, skittish, and fearful. He/she was prepared to be beaten, or threatened, and jumped at any order that was issued by the father. He/she cried incessantly, and exuded an overall attitude of defeat and powerlessness.

At one point in the drama, a local school probation officer (typically a man, but played by a woman) came across the girl buying alcohol for her father in the local trading centre when she should have been in school. The probation officer visited the home and ordered the father to allow his daughter to attend school. The performativity of the probation officer embodied power, authority, and status as an educated male with paid public employment who was in a position to force others to comply with legal requirements. The objects of orientation for the probation officer included a uniform (suit jacket, trousers, and a cap, borrowed from male participants), as well as a motorbike (represented by a broom).

The power differential shifted at the family home when the father was confronted by a more powerful performance of masculinity in the probation officer. The girl was then permitted to go to school. However, because she was much older and much "bigger" than the other students in the class, she was ridiculed by both the students and the (female) teacher for not being able to read, write, or do basic math. The teacher sent her home. It was of interest that the female teacher seemed to lack compassion for the girl, and orientated herself away from the girl. What kind of gender performance was the teacher embodying here? Was it a way to exercise any power she might have as a teacher? Was it to disassociate herself with those who represented the embodied experiences of severe oppression?

These dramatic representations of the challenges that girls face seemed to enable many of the participants to more fully comprehend gender-based abuse and discrimination. 
One male participant expressed a new appreciation for imbalance of work assigned to girls: "The role plays were so interesting. It made me to experience how the girls to work which I had never done". Another commented on how the dramatization helped participants form a more comprehensive understanding of/for the various stakeholders involved in promoting gender equality: "I learned about the roles of stakeholders in the education system especially when we dramatized some stories". What seemed to be the most compelling and interesting aspect of the dramatizations for the participants, however, was the opportunity to experience different gender positionalities and how that shifted their relationships in the world. Some participants commented on insights gained from the more superficial aspects of exploring different gender roles: "it is...useful to do gender activities, e.g., men doing women's work and women do men's work." Some expressed insights related to empowerment: "I enjoyed the drama on gender relations where men and women can do what they thought they could not do"; "In role play many who feel shy to discuss with others were able to speak." Others discussed the helpfulness of role play in gaining an appreciation and understanding of different perspectives: "in this training I gain more knowledge from this role play where by women are able to be like father and man to be like mother." Still others claimed that drama helped them to understand approaches that could be used to promote gender equality in the local context: "in role play it brings the clear picture of what we are supposed to do in promoting gender issues in our community."

Drama enabled the participants' identities and habitus to become entwined within the Discourse of gender in relation to education, as a form of text or "sedimentation" (Rowsell \& Pahl, 2007). During the process of creating the text, the participants disorientated their own experiences and understandings of gender which offered them insight into the power of alignment (empowerment) as well as shifts in alignment (experiencing the different roles of mother/father) within normative gender orientations. In the discussion following the dramas, men who had played female roles admitted to feeling helpless, disrespected, and abused. The women who had assumed male roles felt empowered by the authority they wielded just by virtue of being male, as well as the freedom they had to do certain things are culturally prohibitive to women, such as ride motorbikes. The woman who played the teacher who was seeking sexual favours from the female student discussed how her own personal knowledge of this kind of situation made it easy for her to act out the scenario and it also was informative as she was able to actually understand the kind of power male teachers wielded over vulnerable female students.

The participants believed that dramatizing gender-based challenges was an effective way in which to share, but also personally experience, the complexities of these challenges. As one participant remarked, "The role plays were fantastic and real. I wish the whole world watched the role plays. They would bring in some change." Another (anonymous) individual wrote in the reflective summary of the week's activities, "The role playings were so interesting. It made me to experience how the girls to work which I had not ever done." Another commented on the need for "role play to solve problems," and another observed that it was possible to "pass gender messages to others through stories and skits."

\section{Discussion}

This study sought both to disorient assumptions related to gender normativity in order to expose the elements, processes, and structures that cohere to create something that 
appears to be natural or inherent/inherited. The act of disorienting was not intended to find ways to right the orientation, but rather to unsettle what was familiar in order to open up spaces of possibility for new orientations.

The two-women-one-man discussion strategy effectively disoriented the space of public discourse, where men experienced constraint, and women were able to extend their bodies into a space that was not typically available to them. Initially, the men felt ill at ease, agitated, frustrated, and annoyed, but over the course of the week, the orientation posed less discomfiture for them. The women, too, initially were uncomfortable with the expanse of space available to them, but they became accustomed to orienting themselves towards the power of voice that had become within reach.

The drawings captured objects, performances, and orientations of gender. Drawings clearly depicted the ways in which boys were oriented towards education - towards their teachers, their chairs and desks, the chalkboard; girls were often oriented away from education, and towards objects that would "straighten" their hereditary lines - such as the ground, a child, and clothing that rendered them vulnerable. Gender performativity was evidenced, for example, by male teachers beating female students, and boys sexually and verbally abusing girls. The drawings were instructive in providing artifacts of reference for the discussion of how gendered orientations are foundational to what becomes gender normative.

The dramatic enactments were especially powerful, as they enabled the embodiment of performativity and a full tilt of experienced disorientation. The visceral experience of many of the participants who assumed the roles of the opposite gender seemed to deeply impact them as well as the other participants. The words, gestures, postures, interactions, objects, and ways in which their bodies occupied space were imbued with the corporeal knowledge of what it means to be orientated towards/around/away from material and non-material objects, and how those orientations impact and even determine the lines/paths individuals follow. Interestingly, the women and men who assumed different gender roles did so with surprising ease, as if they intuitively knew what it felt like to be "aligned" with the horizons of gender-constructed space, especially when supported with material objects that reinforced attributes associated with that gender.

Many participants communicated — openly or anonymously in the questionnaires that our explorations into cultural orientations of gender had initiated a paradigmatic shift for them in terms of their understanding of the challenges that girls face: "[I now] understand the problems faced by the girl child especially the big ones during: menstruation, school fees problems, negligent parents, girls that conceive during their school life," and, "[I understand] how gender can be promoted in schools, communities and other institutions." Disorienting gender through embodied, multimodal approaches to text creation and interpretation offered the participants not only new insights into girls' lives and experiences, but also increased understanding of normative gender-based issues, which motivated them to commit to more gender-responsive pedagogical approaches that acknowledged the need for deliberate practices of inclusion and encouragement of all pupils: "As a teacher I need to change methods of teaching in order to cater for the slow learners ... I need to involve all the learners in my class that is girls and boys to participate equal in the activities given." Experiences of disorientation also appeared to cultivate deeper degrees of compassion and empathy that participants indicated would influence their practice: "[I will] teach with mercy trying to understand the learners deeper"; "I as a 
teacher should not harass pupils but solve their problems amicably with their parents for their bright future." Some participants indicated that explorations into disorientations of gender was of continuing interest to them, as evidenced in this comment in the reflective piece, "After I will leave [this course] I will be observing my gender and make sure that I observe the gender roles."

However, there was also recognition that disorienting the status quo was risky and would likely be met with resistance. One male participant, who admitted to me that he had struggled with the challenges that the course had presented to his understanding of gendernormative assumptions, behaviours, and structures, wrote, in his final reflective piece, "I will try to do, implement ... the necessary ideas in my school though I may get some tough times from the community as they may see what I will do as unusual." This comment bespeaks the reality that the deliberate disruption of societal gender norms is a herculean undertaking. Those tasked with bringing about gender equality from within are also being tasked with deconstructing and disorienting the societies to which they belong, and within which their own gendered identities have been created. Thus, working towards achieving gender equality within gender inequitable contexts will undoubtedly be a prolonged, iterative process of disruption and disorientation.

In addition to disorienting gender assumptions, the multimodal approach to participatory research immersed participants in literacy pedagogy that they found to be inspiring for their own teaching. In our final discussion at the conclusion of the course, the participants considered ways in which they would use multimodality in their own teaching practice to engage their pupils in drawing, discussions, drama and other modes of expression. Some reflected upon multimodal practices they would include in the classroom in their final reflective piece: "The knowledge I got from [this course] made me to learn a lot of things, It will made me take a lot of different things in the classroom: telling stories to the children ... different kinds of playing ... drawing pictures will be done; role playing I will introduce"; "The message I will take back to my class/school include...writing gender messages on the compound; organizing some skits about gender in school”.

\section{Conclusion}

This study showed that embodied, multimodal approaches to text and literacy can be used to disorient normative gender assumptions in powerful ways. The interstices pried open by disorientation offer opportunities for non-normative experiences, perceptions, and insights that unsettle the taken-for-grantedness of assumptions and practices based on those assumptions. Policies and programming that promote gender equality in and through education often presume that educators intuitively know what gender equality is and how to facilitate it in the school. Educators, as all individuals, bring their own gendered identities to their work, and this shapes the ways in which they understand their students, their professional relationships, their communities of practice, and their pedagogy.

Teachers inhabit classrooms as individuals with lived experiences, yet unless they are provided with opportunities to deconstruct and disorient gender constructs, they cannot be expected to transform the very society that shaped their own gendered identities. Gender equality in education can only be realized once educators have the opportunity to explore and value their own, and others', embodied experiences of inequality. With this knowledge they can challenge and resist the normalization of inequality and oppression and begin to reshape habitus in their schools (and beyond) to actualize empowerment for girls. 
This study found that, despite the participants' understanding that they were expected to be promoting and operationalizing "gender equality" in their classrooms, and their desire to do so, they did not feel that they possessed the knowledge or tools to do this. The structured discussion response format (two-women-one-man) and the multimodal activities (drawing and drama) supported the participants in the exposing of gender constructs, as well as disorienting those constructs. These processes and experiences enabled them to gain more clarity about the nature and prevalence and often un- or underperceived gender injustices that hindered girls' educational opportunities.

Thus, if educators are expected to operationalize gender equality policies and initiatives in ways that they become truth and reality for children, educators must first, through professional development opportunities, come to know both how gender constructs frame orientations and performativities in ways that present, for example, injustices, opportunities, and power differentials as normative so that these can be deliberately disrupted and disoriented. In addition, educators need to be exposed to effective pedagogies of literacy/literacies that embrace, embody, and value diverse modes of communication so that all voices will have the opportunity to be heard through the semiotic representations they produce through modes of their choosing. Through acknowledging the layers of meaning within sedimentized text, and providing opportunities to uncover and examine these layers, the process of disruption and disorientation can begin to unsettle the normative and open fissures for new gender(ed) identities and relationships.

\section{Acknowledgements}

My sincere gratitude to all the participants of this study who were willing to explore and reflect upon some sensitive and challenging topics and commit to promoting and facilitating gender equality in their schools. Thank you also to Sserwanja Fatumah for assisting with the facilitation of the course. Also, thank you to the Canadian Department for Foreign Affairs and Development for the funding that supported the professional development course. Sincere thanks also to the reviewers of this paper, who provided some excellent feedback, and to Elizabeth Tingle, for her very thorough and thoughtful copy-editing.

\section{References}

Ahmed, S. (2006). Orientations: Toward a queer phenomenology. GLQ: A Journal of Lesbian and Gay Studies, 12(4), 543-74.

Bantebya, G.K., Muhanguzi, F.K., \& Watson, C. (2014). Adolescent girls in the balance: Change and continuity in social norms and practices around marriage and education in Uganda. London: Overseas Development Institute.

Blackden, C.M. (2004). Out of control: Gender and poverty in Uganda. A strategic country gender assessment (Discussion draft). Washington, DC: World Bank.

Bourdieu, P. (1977). Outline of a theory of practice (R. Nice, Trans.). Cambridge, UK: Cambridge University Press.

Bourdieu, P. (1990). The logic of practice. (R. Nice, Trans.). Stanford, CA: Stanford University Press. 
Butler, J. (1988). Performative acts and gender constitutions: An essay in phenomenology and feminist theory. Theatre Journal, 40(4), 519-531.

Chilisa, B., \& Ntseane, G. (2010). Resisting dominant discourses: Implications of indigenous, African feminist theory and methods for gender and education research. Gender and Education, 22(6), 617-632.

Cresswell, J. W. 2008. Educational research: Planning, conducting, and evaluating quantitative and qualitative research (3rd ed.). Upper Saddle River, New Jersey: Pearson.

Faughnan, P. (2016, October 13). Fighting for girls' education in Northern Uganda. Global Partnership for Education. Retrieved from http://www.globalpartnership.org/blog/fighting-girls-education-northern-uganda

Freire, P. (1970). Pedagogy of the oppressed. (M. Ramos, Trans.). New York: Herder and Herder.

Gee, J.P. (1996). Social linguistics and literacies: Ideology in discourses (2nd Ed.). London: Routledge.

Gee, J.P. (1999). An introduction to discourse analysis: Theory and method. London: Routledge.

Government of Uganda (2007). Uganda Vision 2040. Kampala: Author. Retrieved from http://npa.ug/wp-content/themes/npatheme/documents/vision2040.pdf

Grbich, C. (2013). Qualitative data analysis: An introduction (2nd ed.). Thousand Oaks, CA: Sage.

Jewitt, C. (2008). Multimodality and literacy in school classrooms. Review of research in education, 32, 241-267.

Jones, S. K. (2008). Secondary schooling for girls in rural Uganda: Challenges, opportunities, and emerging identities. Retrieved from: https://circle.ubc.ca/handle/2429/279?show=full

Jones, S. (2011). Girls' secondary education in Uganda: Assessing policy within the Women's Empowerment Framework. Gender and Education, 23(4), 385-413.

Jones, S. (2015). Post-primary education, employment, and capabilities: Insights from young women in rural Uganda. African Education Review, 12(1), 127-141.

Kakuru, D. M. 2006. The combat for gender equality in education: Rural livelihood pathways in the context of HIV/AIDS. African Women Leaders in Agriculture and the Environment, AWLAE Series No. 4. Wageningen, The Netherlands: Wageningen University Press.

Kendrick, M., Jones, S., Mutonyi, H., \& Norton, B. (2006). Multimodality and English education in Ugandan schools. English Studies in Africa, 49(1), 95-114.

Kress, G. \& Jewitt, C. (2003). Introduction. In C. Jewitt \& G. Kress (Eds.), Multimodal literacy (pp. 1-18). New York, NY: Peter Lang.

Kress, G. \& van Leeuwen, T. (2001). Multimodal discourses: The modes and media of contemporary communication. London: Arnold.

Kwesiga, J. (2003, November). Review of the 2005 gender parity Millennium Development Goal in Uganda and proposed strategies for achieving this target. Department of Women and Gender Studies, Makerere University, Kampala.

Lather, P. (2004). Issues of validity in openly dialogic research: Between a rock and a soft place. In Y. S. Lincoln \& N. K. Denzin (Eds.), Turning points in qualitative research: Tying knots in a handkerchief (pp. 185-216). Walnut Creek, CA: Altamira. 
Lawson, D. (2003). Gender analysis of the Ugandan National Household Surveys, 19922003. Draft report prepared for the revision of the Poverty Eradication Action Plan, October, 2003.

Longwe, S. W. (2000). Towards realistic strategies for women's political empowerment in Africa. In C. Sweetman (Ed.), Women in leadership (pp. 23-30). Oxford: Oxfam.

Mirembe, R., \& Davies, L. (2001). Is schooling a risk? Gender, power relations, and school culture in Uganda. Gender and Education, 13(4), 401-416.

Mlama, P., Dioum, M., Makoye, H. Murage, L., Wagah, M., Washika, R. (2005). Gender responsive pedagogy: A teacher's handbook. Nairobi: Forum for African Women Educationalists.

Pink, S. (2011). Multimodality, multisensoriality and ethnographic knowing: Social semiotics and the phenomenology of perception. Qualitative Research, 11(3), 261276.

Roswell, J., \& Pahl, K. (2007). Sedimented identities in texts: Instances of practice. Reading Research Quarterly, 42(3), 388-404.

Stoebenau, K., Warner, A., Edmeades, J.D., \& Sexton, M. (2015). “Girls are like leaves on the wind": How gender expectations impact girls' education - a closer look from West Nile, Uganda. Washington, DC: International Center for Research on Women.

The New London Group. (1996). A pedagogy of multiliteracies: Designing social futures. Harvard Educational Review, 66(1), 60-92.

Uganda. Bureau of Statistics (UBOS). (2012). Education sector: Gender statistics profile. Kampala: Author..

Uganda. Bureau of Statistics (UBOS). (2017). Uganda national household survey 2016/17. Kampala: Author..

Uganda. Ministry of Education and Sports (MOES) (2013). National Strategy for Girls' Education. Kampala: Author.

Uganda. Ministry of Gender, Labour, and Social Development (MoGLSD) (2007). The Uganda gender policy. Kampala: Author.

UNESCO Institute for Statistics. (2017). Uganda: Education and literacy. Montreal: Author..

\section{Author Biography}

Dr. Shelley Jones is Associate Professor and Head of the International Year One and the Bachelor of Interdisciplinary Studies programs at Royal Roads University. Shelley has extensive teaching and experience at all levels (pre-primary to tertiary) in diverse international contexts (Uganda, Tanzania, Uganda, Canada, England, and Japan). Shelley's research is focused primarily in the areas of gender and education, girls and women's empowerment, language and literacy, and teacher education. Prior to joining Royal Roads University in 2015, Shelley held the position of Associate Professor at the Aga Khan University-Institute for Educational Development, East Africa (Tanzania) (2013-2015), and Assistant Professor at the State University of New York, College at Potsdam (2009-2013), and was a sessional instructor at the University of British Columbia. Shelley earned her PhD through the Department of Language and Literacy at the University of British Columbia. 
